\title{
ELECTRIC/DIELECTRIC PROPERTIES OF COMPOSITES FILLED WITH ONION-LIKE CARBON AND MULTIWALLED CARBON NANOTUBES
}

\author{
I. Kranauskaitè a , J. Banys ${ }^{\text {a }}$, E. Talik ${ }^{b}$, V. Kuznetsov ${ }^{c}$, N. Nunn ${ }^{d}$, and O. Shenderova ${ }^{d}$ \\ ${ }^{a}$ Vilnius University, Sauletekio 9, LT-00122 Vilnius, Lithuania \\ E-mail: ieva.kranauskaite@ff.vu.lt \\ ${ }^{\mathrm{b}}$ Institute of Physics, University of Silesia, ul. Uniwersytecka 4, PL-40-007 Katowice, Poland \\ 'Boreskov Institute of Catalysis SB RAS, Lavrentiev Ave. 5, Novosibirsk, 630090, Russia \\ ${ }^{\mathrm{d}}$ International Technology Center, Raleigh, NC 27715, USA
}

Received 3 February 2015; revised 6 March 2015; accepted 20 March 2015

\begin{abstract}
The dielectric/electric properties of polyurethane composites filled with carbon nanotubes (CNTs), onion-like carbon (OLC) and mixed onion-like carbon/carbon nanotubes are compared across a wide frequency range from hertz to terahertz. The highest value of dielectric permittivity and electrical conductivity is observed in composites with carbon nanotubes. However, the dielectric/electric properties of composites filled with onion-like carbon are also very attractive and can be improved by addition of small amounts of carbon nanotubes due to the strong synergy effect. In composites with inclusions of mixed onion-like carbon/ carbon nanotubes, the dielectric permittivity and electrical conductivity increase due to the decreasing of both the potential barrier for carrier tunneling and the average distance between nanocarbon clusters.
\end{abstract}

Keywords: carbon nanotubes, onion-like carbon, synergy, composites

PACS: 72.80.Tm, 77.22.Ch, 81.05.ub, 81.07.De

\section{Introduction}

Nowadays, investigations of electrically percolative polymer-based composites with various nanocarbon inclusions are very popular due to their outstanding electric, electromagnetic, mechanical and thermal properties in comparison with the polymer matrix material [1]. Conductive polymer composites find largescale applications as antistatic materials, in printed electronics, supercapacitors, organic solar cells, biosensors,

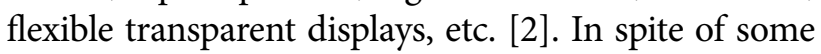
practical limitations due to their limited processability and their manufacturing cost, DC and AC conductive composites are rapidly gaining attention in new applications such as packaging for electronics and chemical industry, metal replacement, heating elements and fuel cells, for electromagnetic shielding and for radar wave absorbing applications in wide frequency ranges [3]. The major field of applications for electrically conductive composites depends on the magnitude of their volume electrical resistivity. For antistatic applications the range should be at the level of $10^{9}-10^{14} \Omega \mathrm{cm}$, whereas for electrostatic dissipation applications the range is expected to be $10^{5}-10^{9} \Omega \mathrm{cm}$.
Many investigations of such composites were performed within a narrow frequency range and at room temperature in order to find the percolation threshold (the minimum concentration of nanofillers at which composites are conductive) [4]. An important task is to obtain a low percolation threshold to preserve (or reach) optimal mechanical properties of polymers and to use a minimal concentration of expensive fillers. The lowest percolation threshold was observed in carbon nanotube (CNT) composites due to their high aspect ratios [5]. However, CNTs usually exhibit large agglomerates within the polymer matrix because of the high van der Waals force between CNTs, and this leads to an increase of the percolation threshold. Therefore, the percolation threshold in the same polymer matrix and for the same CNTs can vary significantly [6]. Moreover, the percolation threshold in other composites, for example, in carbon black (CB) composites, can also be very low 阴. Thus, investigations of composites with other less expensive inclusions are very promising.

Onion-like carbon (OLC), consisting of stable defected multishell fullerenes, exhibits high conductivity similar to CNTs [8]. The percolation threshold in OLC composites is strictly dependent on the aggregate 
size, and it is lowest for composites with the smallest aggregate size [9]. Particularly, in OLC/polyurethane composites with an average aggregate size of $\sim 120 \mathrm{~nm}$, the percolation threshold is $10 \mathrm{vol} \%$ [10]. Thus, the percolation threshold in OLC composites is lower than predicted by Monte-Carlo calculations 31.2 vol\% [11] and can be lowered with optimal composite preparation procedures [12]. Moreover, the dielectric permittivity of OLC based composites is very high (more than $10^{6}$ at low frequencies), and these composites are very attractive for various applications [10]. However, the percolation threshold in OLC based composites is still much higher in comparison with CNT composites.

Multiphase composites with several different fillers in the matrix are very interesting in order to find the so-called synergy effect [13]. Often, the distribution of different fillers within the polymer matrix can be favourable, and electrical transport can occur in different filler network together. When this occurs, the percolation threshold can decrease dramatically [13]. Many investigations of synergy effects were performed in CNT/CB composites, and a significant decrease in the percolation threshold, in comparison with $\mathrm{CB}$ composites, was observed [13-15. Usually, this synergistic effect was investigated only at room temperature.

In this paper we compare the broadband dielectric/ electric properties of composites filled with $12 \mathrm{wt} \%$ of CNT, OLC and mixed CNT/OLC composites at temperatures starting from room temperature down to $26 \mathrm{~K}$. It was demonstrated that the dielectric and electric properties with OLC inclusions can be substantially improved with the addition of CNT.

\section{Experiment}

Polyurethane films with nanoadditives were prepared using Clear Gloss MINWAX ${ }^{ø}$ Fast-Drying Polyurethane. Nanoadditives included multi-walled CNT (20 nm diameter, 5-10 micrometre length) purchased from Amorphous Carbon Materials, Inc. and OLC delivered vacuum anealing of detonation nanodiamonds (DND) [8-10]. Aggregates of DNDs consisting of $5 \mathrm{~nm}$ primary particles were heated in vacuum $\left(10^{-4}\right.$ Torr $)$ at $1650^{\circ} \mathrm{C}$ for $3 \mathrm{~h}$ providing aggregates of OLC with aggregate sizes corresponding to the sizes of the starting DND fractions (approximately $100 \mathrm{~nm}$ ). Stock suspensions of nanoadditives $(\sim 0.5-1.0 \% \mathrm{w} / \mathrm{v})$ were prepared in an alcohol solvent and sonicated with a horn-based sonicator for 5 minutes. $7 \mathrm{~g}$ of polyurethane (PU) were measured out and added to a hot-plate at $120^{\circ} \mathrm{C}$ with magnetic stirring. The alcohol based suspension containing the desired amount and type nanoadditive was then added to the polyurethane. The PU had a volatile mass of $50 \%$, so $7 \mathrm{~g}$ of starting PU provided $3.5 \mathrm{~g}$ of solid upon cur- ing; thus, the amount of the alcohol-nanoadditive suspension that was added corresponded to the desired amount of nanoadditve. After the alcohol suspension was combined with the PU, the alcohol was evaporated from the PU-nanoadditive mixture. The samples were then cast on a teflon substrate and cured at $40^{\circ} \mathrm{C}$. After curing, the samples were annealed at $180^{\circ} \mathrm{C}$ for $0.5 \mathrm{~h}$ in order to obtain better homogeneity. In this paper, composites containing $12 \mathrm{wt} \%$ inclusions of CNT, OLC and mixed CNT/OLC (30-70\% by wt.) were investigated.

The microstructural observations of the composites were conducted using the JEOL-7600F scanning electron microscope.

Complex dielectric permittivity was measured as a function of frequency and temperature using an HP4284A precision LCR meter in the frequency range $20 \mathrm{~Hz}-1 \mathrm{MHz}$. For the low temperature measurements, a helium closed cycle cryostat was used. In the frequency range $1 \mathrm{MHz}-3 \mathrm{GHz}$, dielectric measurements were performed using a vector network analyzer (Agilent $8714 \mathrm{ET})$. In the microwave frequency range from 8 to $53 \mathrm{GHz}$, a home-made waveguide spectrometer was used. The method of a thin rod in the waveguide was used [19]. Cylindrically shaped samples where used for these measurements. Dimensions of the samples were with different radius: in $20 \mathrm{~Hz}-1 \mathrm{MHz}$ frequency range, the radius of samples was about $3 \mathrm{~mm}$, in the $1 \mathrm{MHz}-3 \mathrm{GHz}$ frequency range it was about $0.5 \mathrm{~mm}$, while in the $8-53 \mathrm{GHz}$ frequency range the radius was about $0.1 \mathrm{~mm}$.

In the frequency range from $1 \mathrm{MHz}$ to $53 \mathrm{GHz}$, the measurement accuracy was $\sim 10 \%$. Silver paste was used for creating the contacts. In the terahertz frequency range (from $100 \mathrm{GHz}$ to $3 \mathrm{THz}$ ), a terahertz time domain spectrometer (Ekspla Ltd) based on a femtosecond laser was used for the measurements. The spectrometer is based on the femtosecond laser fiber (wavelength $1 \mu \mathrm{m}$, pulse duration less than $150 \mathrm{fs}$ ) and the GaBiAs photoconductive terahertz emitter and detector. The complex effective permittivity was calculated according to the Fresnel equation. For terahertz measurements plate-like thin samples were used (thickness about $0.5 \mathrm{~mm}$ ). All measurements above $1 \mathrm{MHz}$ were performed only at room temperature. The real part of the complex electrical conductivity was calculated as $\sigma^{\prime}=\omega \varepsilon_{0} \varepsilon^{\prime \prime}$, where $\omega$ is the angular frequency, $\varepsilon_{0}$ is the permittivity of vacuum, and $\varepsilon$ " is the imaginary part of complex effective permittivity.

\section{Results and discussion}

The scanning electron microscopy images of the composites filled with OLC, CNT and OLC/CNT inclusions are presented in Fig. 1. The dispersion of 

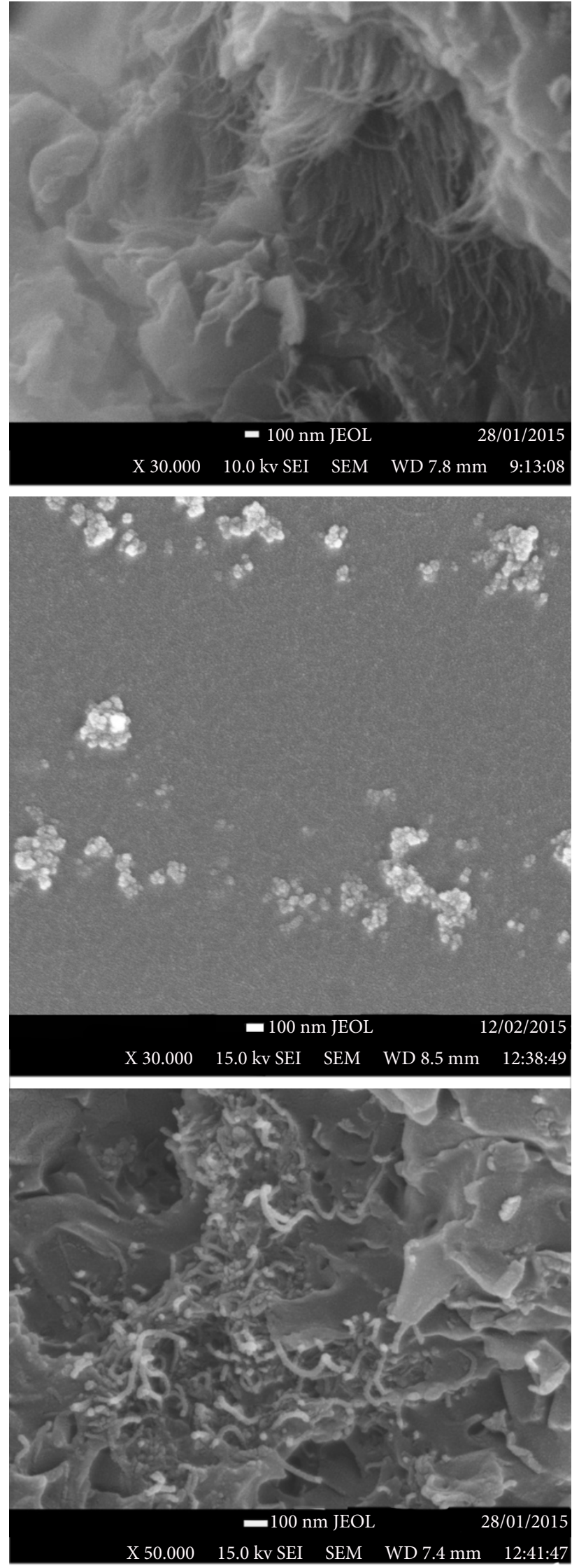

Fig. 1. Scanning electron microscopy image of composites with CNT (top), OLC (middle) and mixed CNT/ OLC (bottom). nano-inclusions in all composites is good enough, however, the best dispersion of nanoparticles is in the mixed OCL/CNT composites.

Frequency dependences of dielectric permittivity and electrical conductivity of all investigated composites and pure polyurethane are presented in Fig. 2.
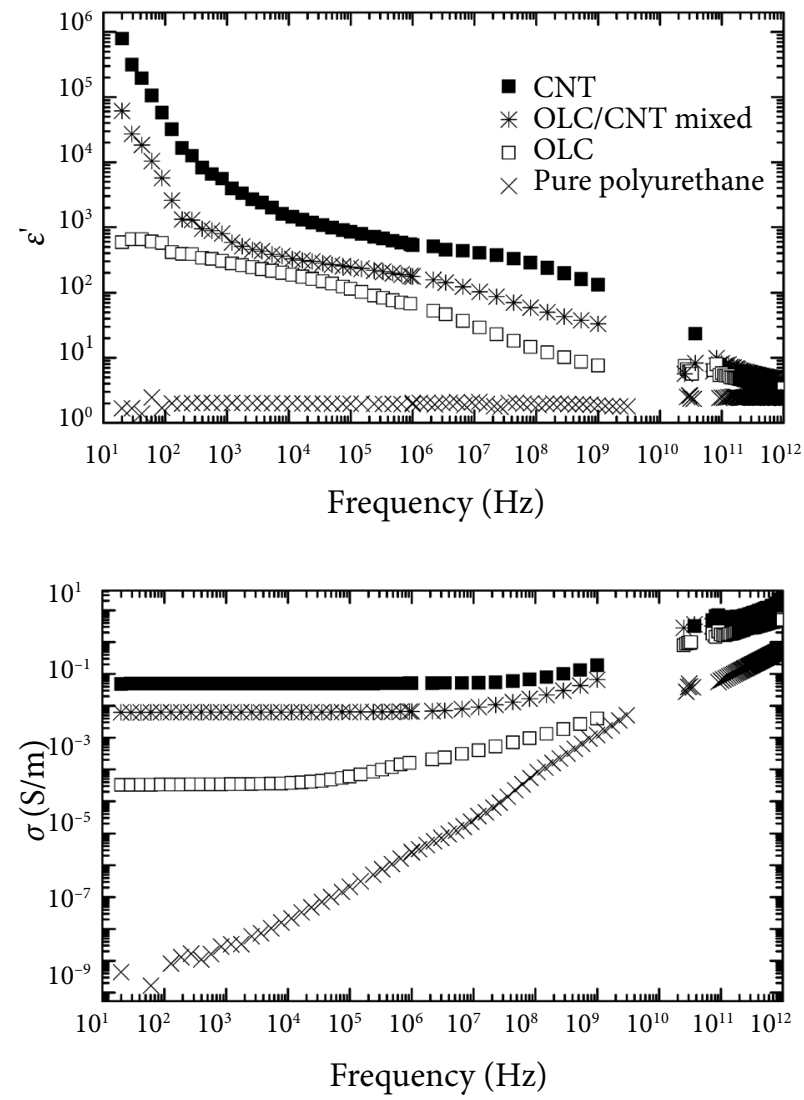

Fig. 2. Frequency dependence of dielectric permittivity and electrical conductivity for composites with various nanocarbon inclusions at room temperature.

The value of the dielectric permittivity of pure polyurethane is very low (about 2), and it is almost frequency independent for all frequency ranges. At low frequencies, the $\mathrm{AC}$ electrical conductivity of pure polyurethane is very low (about $10^{-9} \mathrm{~S} / \mathrm{m}$ ), and no frequency independent conductivity plateau - typical for DC conductivity - is observed. In all composites (with OLC, CNT and CNT/OLC inclusions) the dielectric permittivity is very high (at low frequencies, its value is higher than several hundred). Moreover, at low frequencies the highest value of dielectric permittivity is observed in the CNT based composites $\left(>10^{5}\right)$. At low frequencies, all composites display a frequency independent conductivity plateau; thus, all composites are above the percolation threshold. Nevertheless, we can expect that the lowest percolation threshold value is in the composites with CNT, while the highest value is 
in the composites with OLC inclusions because both the dielectric permittivity and electrical conductivity increase above the percolation threshold in the power law fashion [2]. So, the synergy effect is evident in the system. Thus, even a small part of CNT (30\%) in the mixed OLC/CNT composites can substantially increase the value of the dielectric permittivity and electrical conductivity. For the composites with CNT and OLC/CNT inclusions a frequency independent plateau of dielectric permittivity in the frequency range $1 \mathrm{kHz}-1 \mathrm{MHz}$ separates two different dispersions related with the Maxwell-Garnett relaxation (Fig. 2).

At low temperatures, both the dielelectric permittivity and the electrical conductivity decrease in the OLC/PU composites (Fig. 3).
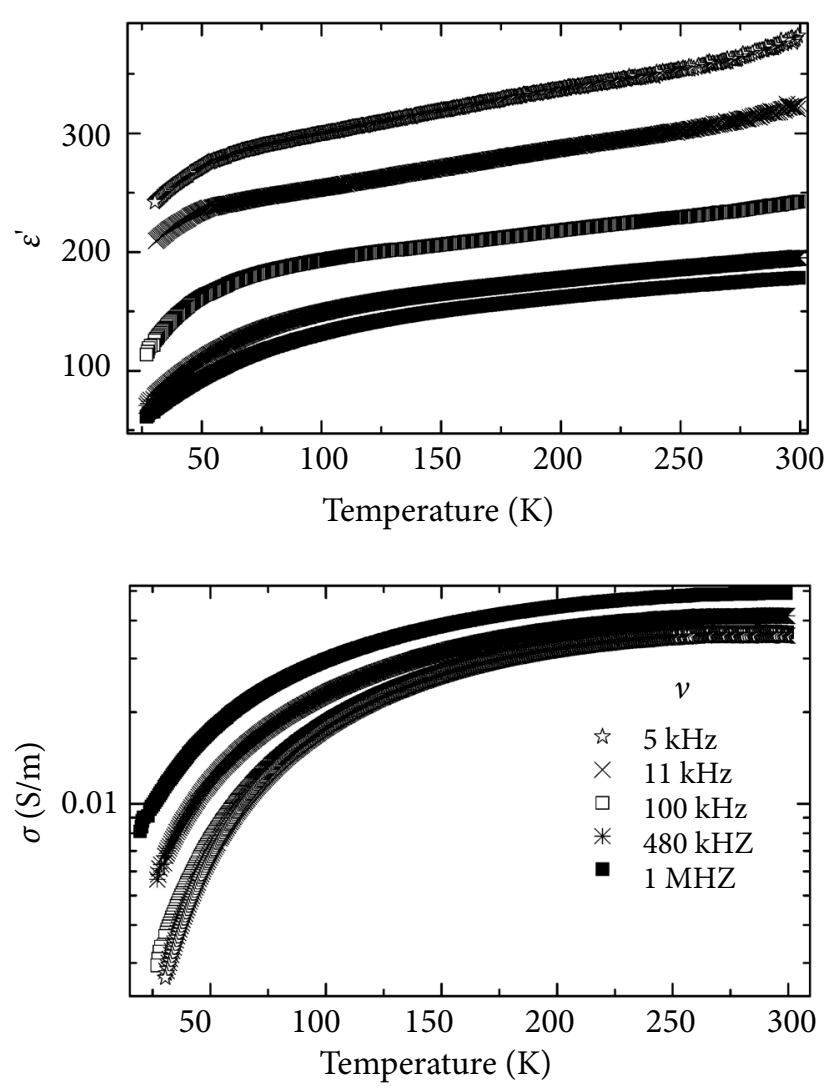

Fig. 3. Temperature dependence of dielectric permittivity and electrical conductivity for composites with OLC inclusions.

However, the most pronounced reduction occurs at temperatures below $100 \mathrm{~K}$. A similar behaviour was observed in the CNT/PU and mixed CNT/OLC/PU composites and is in good agreement with the data presented in literature for composites with nanocarbon inclusions [17, 18]. For the composites with OLC inclusions, not only the DC conductivity changes upon cooling, but the shape of the conductivity spectra is also changed (Fig. 4). Therefore, the conductivity spectra, $\sigma(v)$, were fitted with the Almond-West equation [18]:

$$
\sigma=\sigma_{\mathrm{DC}}+A \omega^{s},
$$

where $\sigma_{\mathrm{DC}}$ is the DC conductivity and $A \omega^{s}$ is the AC conductivity. From this fit, it is possible to calculate the critical conductivity frequency $\left(\omega_{\mathrm{cr}}\right)$ at which the value of frequency dependent conductivity becomes higher than DC conductivity. Experimentally, the value for $\omega_{\text {cr }}$ has been defined as the frequency at which the value of conductivity is $10 \%$ higher than the DC conductivity value.

The critical frequency of the composites with $\mathrm{CNT}$ and CNT/OLC inclusions is higher than $1 \mathrm{MHz}$ (Fig. 4) (our upper frequency limit in low temperature measurements); therefore, the critical frequency values were calculated only for the composites with OLC inclusions.

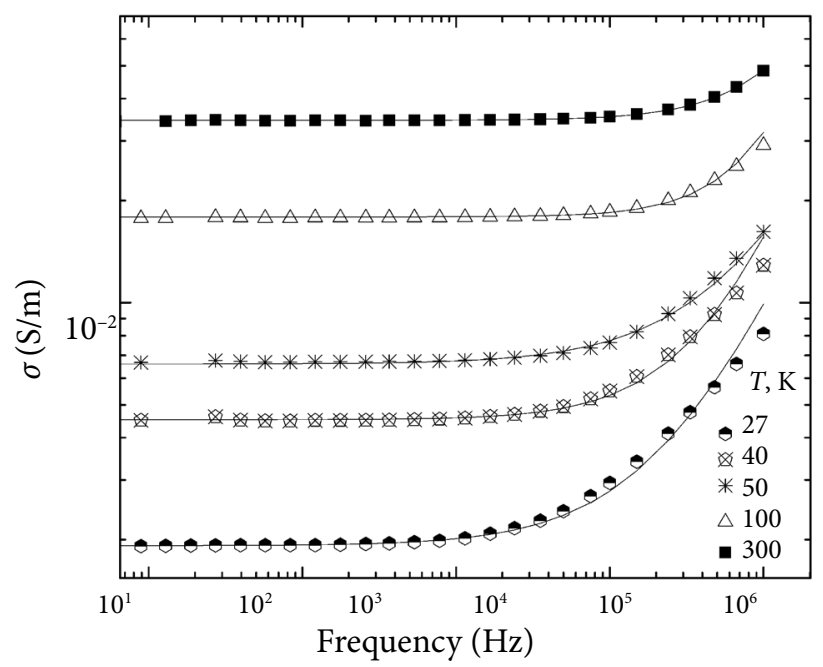

Fig. 4. Frequency dependence of electrical conductivity at different temperatures for composites with OLC inclusions.

The DC conductivity data fit well to the fluctuation induced tunneling model, as can be seen in Fig. 5 [19]:

$$
\sigma_{\mathrm{dc}}=\sigma_{0} \exp \left[-\left[T_{1} / k\left(T+T_{0}\right)\right]\right]
$$

where $T_{1}$ represents the energy required for an electron to cross the insulator gap between the conductive particle aggregates, and $T_{0}$ is the temperature above which thermally activated conduction over the barriers begins to occur. The tunneling model is represented by Eqs. (3) and (4) [19]:

$$
\begin{aligned}
& T_{1}=w A \beta_{0} / 8 \pi k, \\
& T_{0}=2 T_{1} / \pi \chi w,
\end{aligned}
$$


where $\chi=\left(2 m V_{0}\right)^{0.5} / h$ and $\beta_{0}=4 V_{0} / e w, m$ and $e$ are the electron mass and charge, respectively, $V_{0}$ is the potential barrier height, $w$ is the interparticle distance (gap width), and $A$ is the area of capacitance formed by the junction. The obtained parameters are listed in Table 1. From Eqs. (3) and (4) it follows that $T_{1} / T_{0}$ is proportional to the gap width $w$ and the potential barrier $V_{0}$. Thus, they both decrease in the composites filled with mixed CNT/OLC inclusions. The critical frequency $\left(\omega_{\text {cr }}\right)$ is related with DC conductivity according to the Barton-Nakajima-Namikawa relation:

$$
\sigma_{\mathrm{DC}}=\Delta \varepsilon \varepsilon_{0} \omega_{\mathrm{cr}}
$$

where $\Delta \varepsilon$ is the dielectric strength and $\varepsilon_{0}$ is the dielectric permittivity of vacuum.

Table 1. Tunneling model fit parameters.

\begin{tabular}{c|c|c|c}
\hline & $\ln \left\{\sigma_{0}, \mathrm{~S} / \mathrm{m}\right\}$ & $T_{1}, \mathrm{~K}$ & $T_{0}, \mathrm{~K}$ \\
\hline OLC, $12 \mathrm{wt} \%$ & -2.8 & 134 & 12 \\
\hline OLC/CNT, 12 wt\% & -2.5 & 92.9 & 37 \\
\hline CNT, 12 wt $\%$ & -0.6 & 33.2 & 32.8 \\
\hline
\end{tabular}

Thus, for the critical frequency, we have assumed similar temperature dependence as for DC conductivity:

$\omega_{\text {cr }}=\omega_{\text {cro }} \exp \left[-\left[T_{1} /\left(T+T_{0}\right)\right]\right]$.
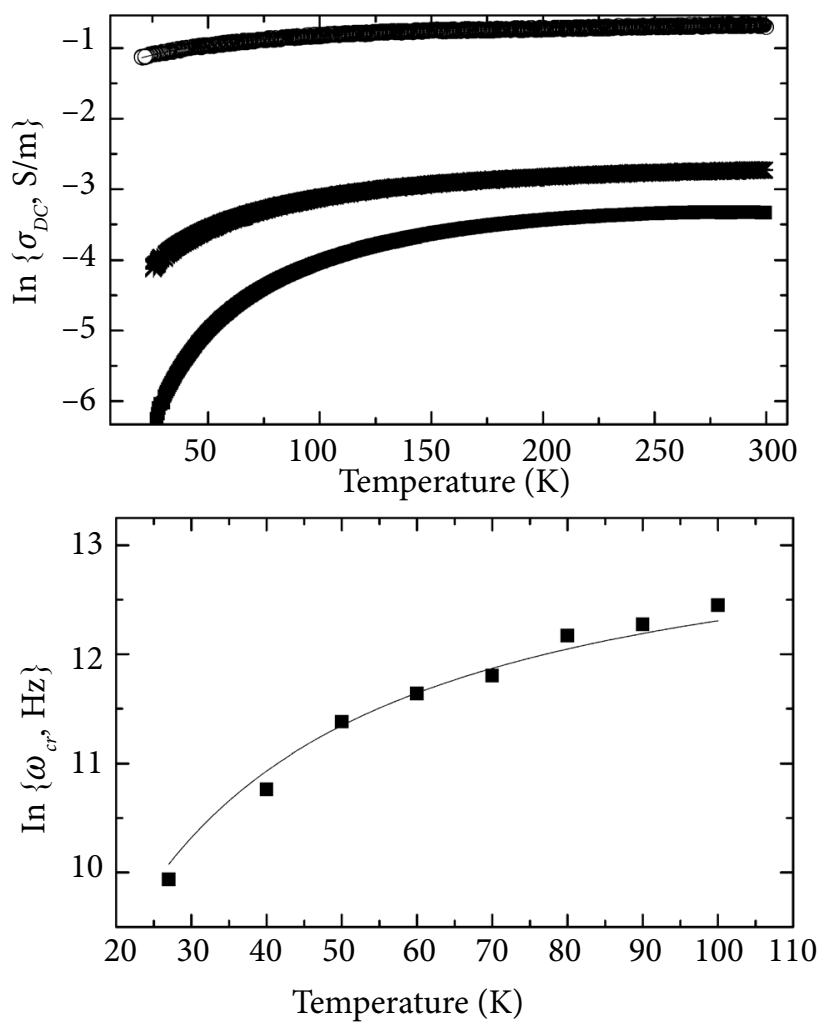

Fig. 5. Temperature dependence of DC conductivity of composites with various nanocarbon inclusions.
For the composites with OLC inclusions, the best fit was obtained with the same values of parameters $T_{1}$ and $T_{0}$ as for DC conductivity and $\omega_{\text {cro }}=729 \mathrm{kHz}$ (Fig. 5).

\section{Conclusions}

The dielectric/electric properties of carbon nanotube (CNT), onion-like carbon (OLC), and mixed onionlike carbon/carbon nanotube (OLC/CNT) polyurethane composites are presented across a wide frequency range from hertz to terahertz. Although the highest dielectric permittivity value is observed in the composites with CNT inclusions, the dielectric properties of composites with OLC inclusions are also very attractive and can be improved by addition of small amounts of CNTs due to the strong synergy effect. In the composites with mixed OLC/CNT inclusions, the dielectric permittivity and electrical conductivity increase due to the reduction of both the potential barrier for carrier tunneling and the average distance between nanocarbon clusters.

\section{Acknowledgements}

This research is funded by the European Social Fund under the Global Grant measure.

\section{References}

[1] F. Qin and C. Brosseau, A review and analysis of microwave absorption in polymer composites filled with carbonaceous particles, J. Appl. Phys. 111, 061301 (2012).

[2] G. Inzelt, Conducting Polymers: A New Era in Electrochemistry (Springer, Berlin, 2008).

[3] K.J. Vinoy and R.M. Jha, Radar Absorbing Materials from Theory to Design and Characterization (Kluwer Academic Publishers, Boston, 1996).

[4] M.J. Jiang, Z.M. Dang, and H.P. Xu, Giant dielectric constant and resistance-pressure sensitivity in carbon nanotubes/rubber nanocomposites with low percolation threshold, Appl. Phys. Lett. 90, 042912 (2007).

[5] W. Bauhofer and Z. Kovacs, A review and analysis of electrical percolation in carbon nanotube polymer composites, Compos. Sci. Technol. 69, 1486 (2009).

[6] L.J. Adriaanse, J.A. Reedijk, P.A.A. Teunissen, H.B. Brom, M.A.J. Michels, and J.C.M. BrokkenZijp, High-dilution carbon-black/polymer composites: Hierarchical percolating network derived from $\mathrm{Hz}$ to $\mathrm{THz}$ ac conductivity, Phys. Rev. Lett. 78, 1755 (1997).

[7] V.L. Kuznetsov, Yu.V. Butenko, A.L. Chuvilin, A.I. Romanenko, and A.V. Okotrub, Electrical 
resistivity of graphitized ultra-disperse diamond and onion-like carbon, Chem. Phys. Lett. 336, 5-6 (2001).

[8] J. Macutkevic, I. Kranauskaite, J. Banys, S. Moseenkov, V. Kuznetsov, and O. Shenderova, Metalinsulator transition and size dependent electrical percolation in onion-like carbon/polydimethylsiloxane composites, J. Appl. Phys. 115, 213702 (2014).

[9] J. Macutkevic, D. Seliuta, G. Valusis, J. Banys, V. Kuznetsov, S. Moseenkov, and O. Shenderova, High dielectric permittivity of percolative composites based on onion-like carbon, Appl. Phys. Lett. 95, 112901 (2009).

[10]S. Kirkpatrick, Percolation phenomena in higher dimensions: Approach to the mean-field limit, Phys. Rev. Lett. 36, 69 (1976).

[11]J. Macutkevic, D. Seliuta, G. Valusis, J. Banys, S. Hens, V. Borjanovic, V. Kuznetsov, and O. Shenderova, Effect of thermal treatment conditions on the properties of onion-like carbon based polymer composite, Compos. Sci. Technol. 70, 2298 (2010).

[12]J. Chen, X. Ch. Du, W.B. Zhang, J.H. Yang, N. Zhang, T. Huang and Y. Wang, Synergistic effect of carbon nanotubes and carbon black on electrical conductivity of PA6/ABS blend, Compos. Sci. Technol. 81, 1-8 (2013).

[13]E. Bilotti, H. Zhang, H. Deng, R. Zhang, Q. Fu, and T. Peijs, Controlling the dynamic percolation of carbon nanotube based conductive polymer composites by addition of secondary nanofillers: The effect on electrical conductivity and tuneable sensing behaviour, Compos. Sci. Technol. 74, 84 (2013).

[14] J. Sumfleth, X.C. Adroher, and K. Shulte, Synergistic effects in network formation and electrical properties of hybrid epoxy nanocomposites containing multi-wall carbon nanotubes and carbon black, J. Mater. Sci. 44, 3241 (2009).

[15]J. Grigas, Microwave Dielectric Spectroscopy of Ferroelectrics and Related Materials (Gordon and Breach Science Publishers, Amsterdam, 1996).

[16]H.M. Kim, M.S. Choi, J. Joo, J.J. Cho, and H.S. Yoon, Complexity in charge transport for multiwalled carbon nanotube and poly(methyl methacrylate) composites, Phys. Rev. B 74, 054202 (2006).

[17]J. Macutkevic, R. Adomavicius, A. Krotkus, J. Banys, V. Kuznetsov, S. Moseenkov, A. Romanenko, and $\mathrm{O}$. Shenderova, Localization and electrical transport in onion-like carbon based composites, J. Appl. Phys. 111, 103701 (2012).

[18] D. Almond, G.K. Duncan, and A.R. West, The determination of hopping rates and carrier concentrations in ionic conductors by a new analysis of ac conductivity, Solid State Ionics 8, 159 (1983).

[19] P. Sheng, E.K. Sichel, and J.I. Gittleman, Fluctuation-included tunneling conduction in carbonpolyvinylchloride composites, Phys. Rev. Lett. 40, 1197 (1978).

\title{
KOMPOZITŲ SU SVOGŪNINĖS ANGLIES IR DAUGIASIENIUU ANGLIES NANOVAMZDELIŲ UŽPILDU ELEKTRINĖS IR DIELEKTRINÉS SAVYBĖS
}

\author{
I. Kranauskaite a , J. Banys ${ }^{\text {a }}$, E. Talik ${ }^{\text {b }, ~ V . ~ K u z n e t s o v ~}{ }^{c}$, N. Nunn ${ }^{\text {d }}$, O. Shenderova ${ }^{d}$ \\ ${ }^{a}$ Vilniaus universitetas, Vilnius, Lietuva \\ b Silezijos universiteto Fizikos institutas, Katovicai, Lenkija \\ ${ }^{\mathrm{c}}$ Rusijos MA Sibiro skyriaus Boreskovo katalizès institutas, Novosibirskas, Rusija \\ ${ }^{\mathrm{d}}$ Tarptautinis technologijos centras, Rolis, Šiaurès Karolina, JAV
}

\section{Santrauka}

Straipsnyje aptariamos kompozitu su anglies nanovamzdelių, svogūninès anglies, mišriu nanovamzdelių ir svogūninès anglies užpildu plačiame dažnių diapazone elektrinès bei dielektrinès savybès.

Kompozituose su anglies nanovamzdeliais yra stebimos didesnès dielektrinès skvarbos ir laidumo vertès nei kompozituose su svogūninès anglies užpildu. Kompozitų su svogūninès anglies užpildu elektrinès savybès gali būti pagerintos ịterpiant nedideli kieki anglies nanovamzdelių. Mišriuose kompozituose dèl sumažejusio atstumo tarp anglies intarpų mažeja potencinis barjeras elektronams tuneliuoti, todèl padidèja kompozitų dielektrinè skvarba ir elektrinis laidumas. 